\title{
Carta al editor con respecto al artículo: "Negligencia: modalidad subestimada del maltrato al infante"
}

\author{
Letter to the editor in relation to the article: Neglect: \\ underestimated frorm of child abuse
}

\section{Estimado Dr. Francisco Espinosa Rosales}

(Editor en Jefe de Acta Pediátrica de México)

He leído con sumo interés el artículo: "Negligencia: modalidad subestimada del maltrato al infante" de la Dra. Mónica Rodríguez González y del Dr. Arturo Loredo Abdalá debido a que hay muy poco escrito en la literatura nacional sobre este tópico y tomando en cuenta que es una modalidad del maltrato infantil extraordinariamente frecuente, pero poco entendida y estudiada por los medios que atienden niños.

Me pareció interesante el artículo ya que los autores al hablar de esta modalidad de maltrato infantil también dan luz sobre las diversas manifestaciones clínicas y las repercusiones en la salud física y emocional en las víctimas a corto, mediano y largo plazo.

Me parece que es de suma importancia su divulgación porque es la modalidad de maltrato infantil más prevalente y, por ende, la más difícil de diagnosticar si consideramos sus diversas manifestaciones clínicas y la probable falta de conocimiento que puedan tener los médicos que atienden niños.

Aunque en el artículo los autores citan seis definiciones de negligencia, casi todas ellas dependientes de diferentes organizaciones mundiales o de expertos en el tema, tengo la impresión de que todas carecen de tres aspectos que son básicos del problema, a saber:
Pasante del Servicio Social por la Facultad de Medicina de la Universidad Nacional Autónoma de México, Ciudad de México, México.

Correspondencia Óscar Gabriel Carballido Moreno gabo_carballido@hotmail.com

Este artículo debe citarse como Carballido-Moreno OS. Carta al editor con respecto al artículo: "Negligencia: modalidad subestimada del maltrato al infante". Acta Pediatr Mex. 2109;40(5):299-300. 
a. Ninguna definición precisa la "intencionalidad" que tienen los padres o cuidadores para atender adecuadamente a una niña, niño o adolescente.

b. Otra carencia básica se puede señalar en la definición de Polanski, ya que dicho autor no considera el componente socioeconómico de los padres o cuidadores.

c. En las definiciones consideradas no se menciona la repercusión física y emocional que desarrolla la víctima a corto, mediano o largo plazo.

En la Clínica de Atención Integral al Niño Maltratado (CAINM-INP) se desarrolló una definición general de maltrato infantil, la que he tomado como base para proponer a los autores la siguiente:
"Negligencia es la omisión intencional, única o repetida de los padres o cuidadores de una niña, niño o adolescente para cubrir las necesidades básicas de vida a pesar de que los responsables cuentan con los recursos económicos y sociales para tal fin. Considerando que dicha omisión, repercute en grado variable sobre el desarrollo bio-psico-social de la víctima a corto, mediano y largo plazo".

Esperando que esta consideración pueda contribuir de alguna manera al conocimiento y a la difusión de esta modalidad del maltrato infantil, les reitero a los autores mis más finas consideraciones.

Atentamente

MPSS. Óscar Gabriel Carballido Moreno 